\title{
A Modified Lightly Doped Drain Structure for VLSI MOSFET's
}

\author{
SERGIO BAMPI, STUDENT MEMBER, IEEe, AND JAMES D. PLUMMER, FELLOW, IEEE
}

\begin{abstract}
A new n-MOS LDD-like device structure (the J-MOS transistor) is proposed. Its design, simulation, and fabrication are studied in this paper. n-channel MOSFET's with $L_{\text {eff }}$ below $2 \mu \mathrm{m}$ suffer from high-field effects that must be overcome to secure reliable 5-V operation. LDD structures alleviate these effects, but their reliability is better than that of conventional MOSFET's only if the $\mathrm{n}^{-}$regions have a peak doping density above $1 \times 10^{18} \mathrm{~cm}^{-3}$. To overcome this limitation and to allow constant voltage scaling for devices into the submicrometer regime, the J-MOS structure uses a series drain JFET to drop part of the supply voltage. Both 2-D device simulations and experimental results are presented to demonstrate the operation of this device and its potential for applications requiring reliable submicrometer device operation under maximum supply voltage. The major experimental findings are that the J-MOS structure can sustain 5-V operation even for submicrometer effective channel lengths. As has been the case with all LDD-like structures, improved device reliability has been achieved at the expense of some performance. However, the advantages of keeping 5-V operation in micrometer-sized devices may outweigh this performance loss.
\end{abstract}

\section{INTRODUCTION}

$\mathrm{P}$ AST EXPERIENCE in MOSFET scaling has shown that device design has proceeded under constraints other than those suggested by constant electric field scaling principles [1]. Alternative scaling approaches [2]-[4] have been used instead, which have allowed continued scaling under constant supply voltage. The shrinking of device dimensions while keeping supply voltage constant offers circuit and system performance advantages, in addition to compatibility with the established 5-V standard. This leads inevitably to higher electric fields inside the active regions of the transistors. The operation of micrometer and submicrometer MOSFET's in the presence of high-field effects has called for innovation in their design so that acceptable device punchthrough voltage and long-term device reliability are maintained as MOSFET's are scaled. In particular, several LDD-like drain structures with the schematic cross sections of Fig. 1 have been studied and compared for use in VLSI circuits as substitutes for the conventional $\mathrm{n}^{+}$As drain. Careful engineering of the drain region in n-channel devices is more important than in p-channel devices because electrons in $\mathrm{Si}$

Manuscript received April 1, 1986; revised July 18, 1986. This work was partially supported by DARPA under Contract MDA903-84-K-0062. $S$. Bampi was supported under a scholarship from CNPq-Brazilian Research Council.

The authors are with the Integrated Circuits Laboratory, Department of Electrical Engineering, Stanford University, Stanford, CA 94305.

IEEE Log Number 8610700.

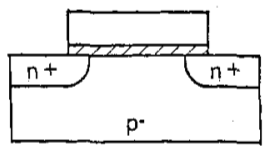

(a)

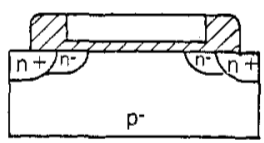

(c)

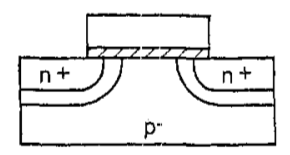

(b)

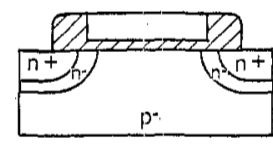

(d)
Fig. 1. Schematic cross-section of (a) conventional, (b) double diffused drain, (c) "inside" LDD, and (d) "outside" LDD n-channel device structures.

have a higher impact ionization rate, a lower energy barrier to injection into the oxide at the $\mathrm{Si}-\mathrm{SiO}_{2}$ interface, and experience drift velocity saturation at smaller fields than holes. High-field effects are then much more harmful to n-channel device performance and reliability. Since device degradation [5]-[8] is related to heating of carriers as they traverse regions of field strength in excess of 100 $\mathrm{kV} / \mathrm{cm}$, reducing electric fields at the drain end of the channel is crucial in n-channel devices. LDD designs for submicrometer p-channel devices have also been proposed [9], mostly for reasons of punchthrough prevention.

In both the LDD FET [10]-[20] and the graded S/D [21]-[27] or double-diffused drain (DDD) n-channel structures of Fig. 1, the narrow $\mathrm{n}^{-}$regions that are introduced between the channel and the $\mathrm{n}^{+}$source-drain are designed to spread the high electric field at the drain into the $\mathrm{n}^{-}$region. Other device structures using a non-selfaligned separate gate, buried channel, or lightly doped S/D have also been proposed [28]-[32]. The reduction and/or spreading of the peak E-field in self-aligned LDDlike structures normally results in an increased reliability insofar as hot-electron-induced instabilities are concerned. However, if the $\mathrm{n}^{-}$surface doping $\left(N_{S}\right)$ is too light, i.e., $N_{S}<10^{18} \mathrm{~cm}^{-3}$, the LDD FET's can actually exhibit poorer reliability than conventional arsenic-doped $\mathrm{n}^{+} \mathrm{S} / \mathrm{D}$ transistors in addition to increased series resistance. This LDD related degradation has been shown to be caused by hot-carrier injection into the sidewall oxide region [33]-[36]. This is shown as process (2) in Fig. 2. It leads to excessive series resistance and degradation rates faster than conventional designs [33], [34]. At an optimum $\mathrm{n}^{-}$doping level, process (1) of Fig. 2 should dom- 


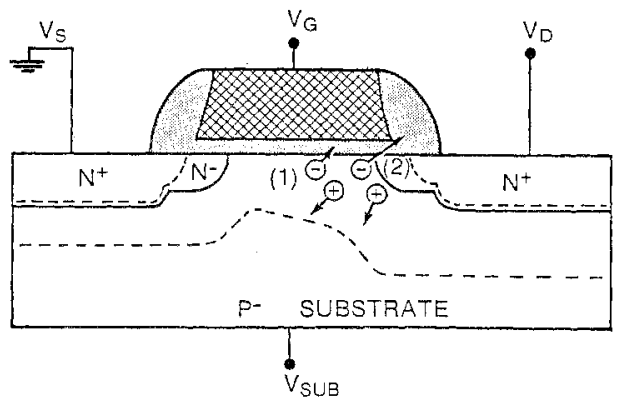

Fig. 2. n-type LDD MOSFET device structure. Hot-carrier injectios occurs either (1) under the gate or (2) over the $\mathrm{n}^{-}$region under the sidinvall oxide.

inate as the longitudinal E-field peaks under the gate. The $\mathrm{n}^{-}$resistive region of optimized LDD FET's spreads sund reduces the peak value of the longitudinal electric lield along the channel length, but the $\mathrm{n}^{-}$region under the sidewall oxide must still remain undepleted for the af orementioned reliability reasons. While peak substrate surrent is usually reduced with a lighter $\mathrm{n}^{-}$dose, charateristics of LDD devices can deteriorate more rapidly ' $x$ ith $\mathrm{n}^{-}$doses $<10^{13} \mathrm{~cm}^{-2}$ [20], [33], [34], [36], [37]. Optimum LDD designs have been studied extensively, and for practical junction depths and $S / D$ anneal temraratures, the optimum $N_{S}$ is $1-2.5 \times 10^{18} \mathrm{~cm}^{-3}[20],[38]$, or, alternatively, the optimum $\mathrm{n}^{-}$dose is $\simeq 1-2 \times 10^{13}$ $\mathrm{cm}^{-2}$ for "inside" LDD's of the type shown in Fig. 1 $[36],[39],[40]$. Other studies have proposed that a b stter $I_{\text {SUB }}$ and device degradation trade-off for "inside" LIID's occurs with either a moderately doped $\left(4-10 \times 10^{13} \mathrm{cln}^{-2}\right)$ phosphorus $\mathrm{n}^{-}$region [41] or with an $\mathrm{As} / \mathrm{P}$ graded $\mathrm{n}$ region [42]. Other studies have suggested optimum $\mathbf{n}^{-}$implant doses of $\approx 5-20 \times 10^{13} \mathrm{~cm}^{-2}$ for both "outs de" LDD's (Fig. 1(d)), [43], and DDD MOSFET's (Fig. (b)) [40], [44]. Analytical models [45], [46] have predicted breakdown voltage improvements of less than 2 and $1 \mathrm{~V}$ for DDD and "inside" LDD devices, respectively, for the range of optimum $\mathbf{n}^{-}$doping levels given above.

\section{JMOS Device Structure}

In the search for reliable VLSI MOSFET's one stould recognize the importance of both reducing high fields inside the device, and also keeping high fields as far iway as possible from the most sensitive MOSFET region which is the $\mathrm{Si}-\mathrm{SiO}_{2}$ interface. Most device instabilities are the result of damage to the gate oxide. In the J/2ETMOSFET (JMOS) structure that we have proposed [47], shown in Fig. 3, one seeks to keep the field peak iway from the region under the gate, and at the same time force the electron current below the surface in the critical high field region near the drain. This should have the effect of minimizing hot-carrier trapping in the gate or sidiswall spacer $\mathrm{SiO}_{2}$ regions. Other authors have also showr that LDD's can perform more reliably by diverting the :hannel current away from the $\mathrm{SiO}_{2}$ interface in the high field drain region. Techniques proposed to accomplish this include either a buried-channel device with a lightly coped

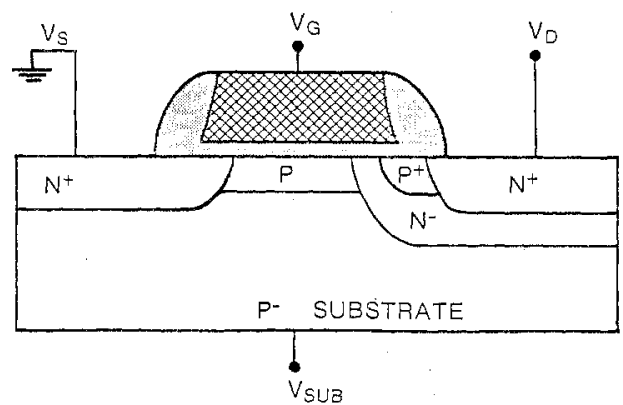

Fig. 3. The n-type JFET-MOSFET (JMOSFET) device structure.

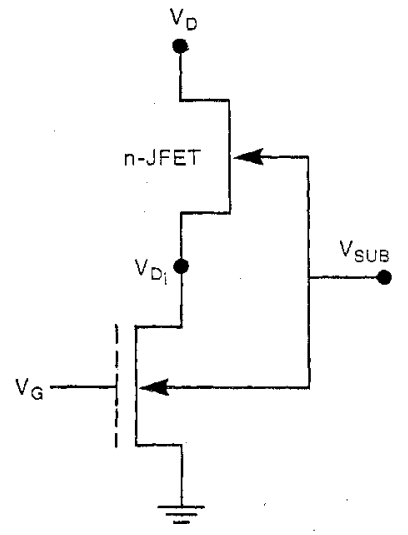

Fig. 4. Equivalent circuit model for the JMOSFET device.

drain [48] or a retrograde $\mathrm{n}^{-}$profile for the LDD region [49]. Other MOSFET device structures have been proposed, like the buried-drain D-MOSFET [50], for which the reliability potential in VLSI has not yet been assessed.

If a more reliable device structure can be designed, then an increase in power supply voltage or a reduction in MOSFET channel length at a given voltage to achieve a performance enhancement is possible. The proposed structure in Fig. 3 has a short-channel JFET at the drain end. The JFET physically occurs because of the presence of a $\mathrm{p}^{+}$region acting as the JFET gate above the $\mathrm{n}^{-}$drain region (Fig. 3). The $\mathrm{p}^{+}$implant connects electrically to the substrate by overlapping the channel stop implant in the transverse direction. The circuit model for such device is shown in Fig. 4. The JFET under the sidewall oxide is fully merged into the MOSFET structure and does not require extra silicon area. It does require a minimum of one extra mask in the process.

\section{Device Simulation}

The JMOS circuit model of Fig. 4 was simulated using SPICE and the transfer function $V_{D_{i}}$ versus $V_{D}$ is plotted in Fig. 5, where $V_{T J}$ is the JFET threshold voltage, $V_{D_{i}}$ is the effective drain bias on the intrinsic MOSFET, and $V_{D}$ is the externally applied drain bias. The HPSPICE MOSFET level 3 and JFET model parameters used are listed in Table I. The simulation suggests that by appropriately choosing the JFET pinchoff voltage $V_{p}$, the device designer can limit the maximum drain bias across the surface-channel MOSFET. Thus, the JMOS device provides 


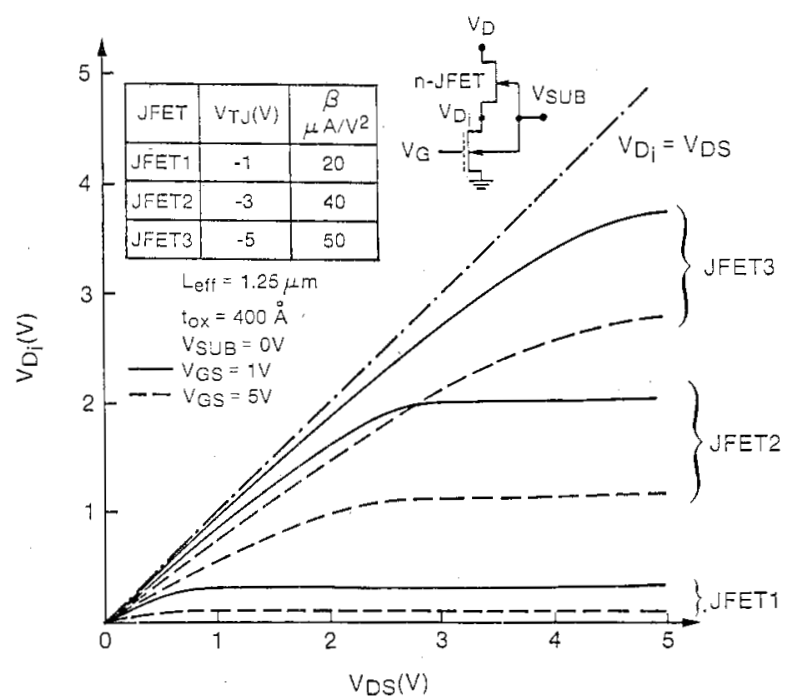

Fig. 5. Relationship between the externally applied JMOSFET drain bias $\left(V_{D S}\right)$ and the voltage at the intrinsic drain of the surface channel MOSFET $\left(V_{D_{i}}\right)$ for three different JFET designs.

TABLE I

\begin{tabular}{|c|c|c|c|}
\hline \multicolumn{4}{|c|}{ MOSFET DEVICE PARAMETERS } \\
\hline Name & Symbol & Value & Unit \\
\hline Low field mobility & $\mu_{0}$ & 665 & $\mathrm{~cm}^{2} V^{-1} \sec ^{-1}$ \\
\hline Oxide thickness & $t_{0 x}$ & 393 & $\AA$ \\
\hline Transconductance factor & $K_{P}$ & 58.5 & $\mu A V^{-2}$ \\
\hline Threshold voltage & $V_{T_{p}}$ & 0.32 & $V$ \\
\hline Effective substrate doping & $N_{S U B}$ & $9.1 \times 10^{15}$ & $\mathrm{~cm}^{-3}$ \\
\hline Body factor & $\gamma$ & 0.515 & $V^{-1 / 2}$ \\
\hline$\left(L_{m, a s k}-L_{e f f}\right) / 2$ & $\frac{1}{L_{D}}$ & 0.25 & $\mu m$ \\
\hline Gaie field mobility factor & $\Theta\left(V_{N O R M}^{T}\right)$ & 0.061 & $V^{-1}$ \\
\hline Longitudinal field mob. factor & $E_{T F H}$ & $7.3 \times 10^{4}$ & $V \mathrm{~cm}^{-1}$ \\
\hline Critical field & $E_{C R T}$ & $1.7 \times 10^{4}$ & $V \mathrm{~cm}^{-1}$ \\
\hline Saturated drain conductance & $D E_{S A T}$ & $7.9 \times 10^{5}$ & $V \mathrm{~cm}^{-2}$ \\
\hline \multicolumn{4}{|c|}{ JFET DEVICE PARAMETERS } \\
\hline Threshold voltage & $V_{T_{1}}$ & $-1,-3,-5 *$ & $\mathrm{~V}$ \\
\hline Transconductance factor & $\beta$ & $20,40,50^{*}$ & $\mu A V^{-2}$ \\
\hline Channel length modulation & $\lambda$ & 0.05 & $V^{-1}$ \\
\hline
\end{tabular}

a means of minimizing hot-carrier problems imposed by constant voltage scaling [7], since the series JFET can be designed to support part of the drain supply. When the MOSFET channel is conducting current, the inequality

$$
V_{D_{i}}<\left(\left|V_{p}\right|-\phi_{b i}-\left|V_{\text {SUB }}\right|\right)=V_{\text {SUB }}-V_{T_{J}}
$$

holds, where $V_{p}$ is the JFET region pinchoff voltage, and $\phi_{b i}$ is the $\mathrm{p}^{+}-\mathrm{n}^{-}$junction built-in potential. In practical designs $V_{p}, V_{T_{J}}$, and $V_{\mathrm{SUB}}$ are $\leq 0$.

Limiting $V_{D_{i}}$ could also be accomplished, of course, by reducing the supply voltage. However, this has important drawbacks since such a reduction leads to compatibility problems, to smaller noise margins in circuits, and to reduced $\left(V_{G S}-V_{T}\right)$ MOSFET drive. Less gate drive often implies slower circuits. The presence of a series drain JFET in the JMOS device allows the full supply to be used on the $V_{D}$ and $V_{G}$ terminals, while the internal voltage of the MOSFET drain is reduced. Conventionally designed micrometer-sized n-MOSFET's in fact need drain biases of less than $3 \mathrm{~V}$ in order for the channel current to saturate in the practical range $0<\left(V_{G S}-V_{T}\right)<5 \mathrm{~V}$, as shown in Fig. 6. This is simply the effect of saturation of

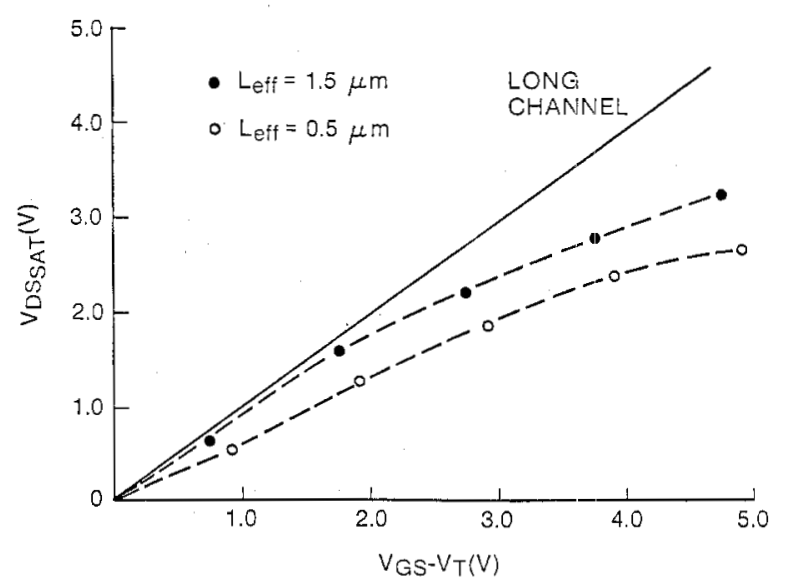

Fig. 6. Saturation drain voltage dependence on $V_{G S}-V_{T}$ for a conventional n-channel MOSFET.

the channel electron average velocity $\langle v\rangle$. Submicrometer devices operating in this saturated velocity regime will have a drain saturation current given by

$$
I_{D S_{\text {sat }}}=W\langle v\rangle C_{\mathrm{ox}}\left(V_{G S}-V_{T}\right)
$$

where $\langle v\rangle \simeq v_{\text {sat }}$ (the optical phonon scattering limited drift velocity for bulk transport).

The drain JFET device, once it pinches off, limits the JMOS current approximately to its first order pinchoff limit $I_{p}[51]$

$$
\begin{aligned}
& I_{p}=W I_{p 0}\left(1-\left(\frac{\phi_{b i}+V_{D_{i}}+\left|V_{\text {SUB }}\right|}{\left|V_{p}\right|}\right)\right)^{2} \\
& I_{p 0}=\frac{\left|V_{p}\right|}{n \rho_{s} L_{s w}}
\end{aligned}
$$

where $n(2<n<3)$ accounts for the nonuniform doping profile in the $\mathrm{n}^{-}$JFET channel, $\rho_{s}(\Omega / \square)$ is the buried $\mathrm{n}^{-}$ sheet resistivity, $L_{s w}$ is the sidewall spacer width-an approximate measure of the JFET effective electrical channel length-and $V_{D_{i}}\left(V_{G S}\right)$ is the gate-voltage-dependent effective MOSFET drain or effective JFET source voltage, according to the lumped circuit model proposed to describe the JMOS device. Equation (3) neglects short JFET channel length effects that are more important when the $\mathrm{n}^{-}$doping is lighter. $I_{p 0}$ depends on the technology design of the vertical impurity profile of the drain JFET, as well as the sidewall spacer width

The JMOS device was simulated by the PISCES 2-D program [52], [53] coupled to impurity profiles simulated in 1-D by SUPREM-III [54]. Two-dimensional device simulations have been widely used as useful tools to guide and better understand the deisgn of LDD devices [55]. Fig. 7 shows the depletion region boundaries for the JMOS device under a bias condition in which the JFET under the sidewall oxide is in its linear region of operation. In this mode, the $\mathrm{n}^{-}$region behaves as a series pinched resistor, or as a buried LDD structure. In Fig. 8 , calculated equipotential contours show the saturation properties of the drain JFET. For those biases in which 


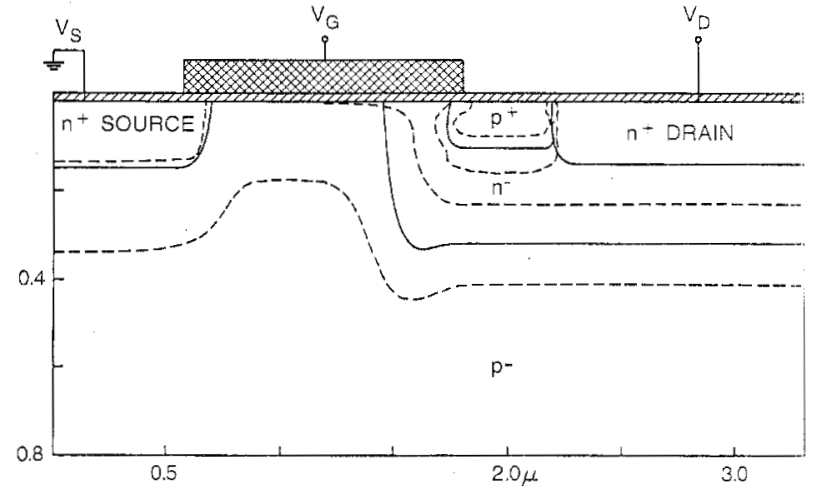

Fig. 7. PISCES simulated depletion boundaries for the JMOSFET with $L_{\text {eff }}=0.72 \mu \mathrm{m}, t_{\mathrm{ox}}=200 \AA, V_{T_{J}}=-1.6 \mathrm{~V}, V_{\mathrm{SUB}}=0 \mathrm{~V}$. Linear region bias of JFET. $V_{D S}=0.1 \mathrm{~V}, V_{G S}=1 \mathrm{~V}$.

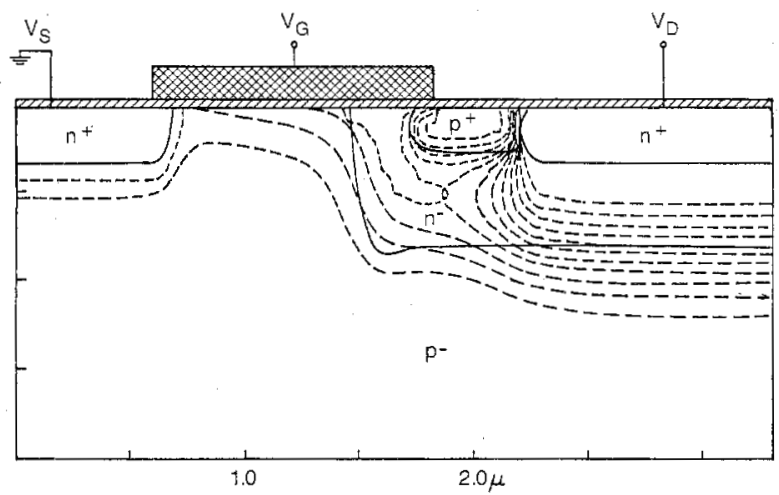

Fig. 8. PISCES simulated equipotential contours for the JMOSFET of Fig. 7. JFET is pinched off at $V_{D S}=V_{G S}=5 \mathrm{~V}$.

the JFET is on and pinched off, i.e.

$$
\left(V_{D S}-V_{\mathrm{SUB}}\right) \geq\left|V_{T_{J}}\right|
$$

the saturated JFET limits the current in the device to the value of $I_{p}\left(V_{G S}\right)$ given by (3). For the simulated device of Fig. $8, V_{T J}=-1.6 \mathrm{~V}, V_{D S}=5 \mathrm{~V}, V_{\mathrm{SUB}}=0 \mathrm{~V}$. "The JFET pinchoff region then supports most of the $5-\mathrm{V}$ diain bias on this particular JMOS design, while the surface channel MOSFET supports less than $1 \mathrm{~V}$. As suggested by the simulated potential contours under the $\mathrm{SiO}_{2}-\mathrm{Si}$ interface, and as we shall demonstrate experimentally, his will result in a large reduction in impact ionization uncler the MOSFET gate compared to a conventional derice structure. The electron and net donor densities, and the electrostatic potential along the $\mathrm{Si}-\mathrm{SiO}_{2}$ interface in the JMOS device are shown in Fig. 9(a) and Fig. 9(b), respectively. The peak longitudinal E-field at the gate $\mathrm{Si} \mathrm{J}_{2}-$ Si interface is kept below $5 \times 10^{4} \mathrm{~V} / \mathrm{cm}$, which is one order of magnitude smaller than typical peak fields at the drain end of pinched off conventional MOSFET's [56][58].

PISCES simulated $I-V$ characteristics are shown in F'ig. 10 for the device of Fig. 8. In this JMOS device the onset of saturation is independent of $V_{G S}$ since the drain JFET pinches off at the drain voltages for which (5) is an equality. In this case the JFET operates as a current-limiting device fully merged into the LDD region. The PISC IES
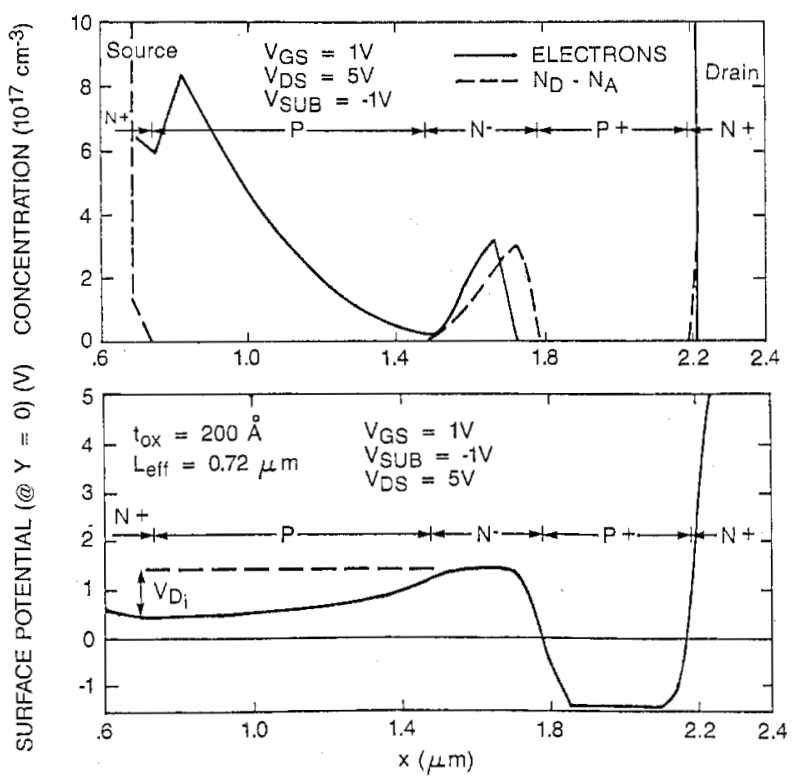

(b)

Fig. 9. PISCES simulations of the JMOS structure of Fig. 7: (a) Electron and net donor densities along the $\mathrm{Si}-\mathrm{SiO}_{2}$ interfaces; (b) Potential along the $\mathrm{Si}_{-} \mathrm{SiO}_{2}$ interface. $V_{\mathrm{SUB}}=-1 \mathrm{~V}, V_{D S}=5 \mathrm{~V}, V_{G S}=1 \mathrm{~V}$.

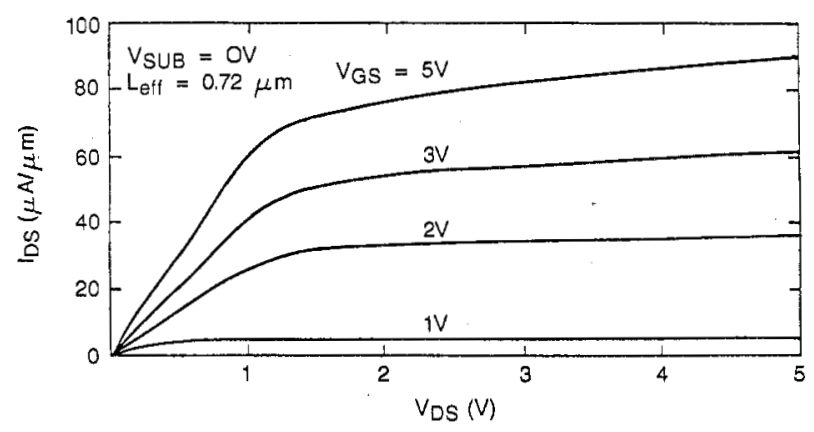

Fig. 10. PISCES simulated $I_{D S}$ versus $V_{D S}$ for $V_{T_{J}}=-1.6 \mathrm{~V}$. JMOSFET structure of Fig. 7. $V_{\text {SUB }}=0 \mathrm{~V}$.

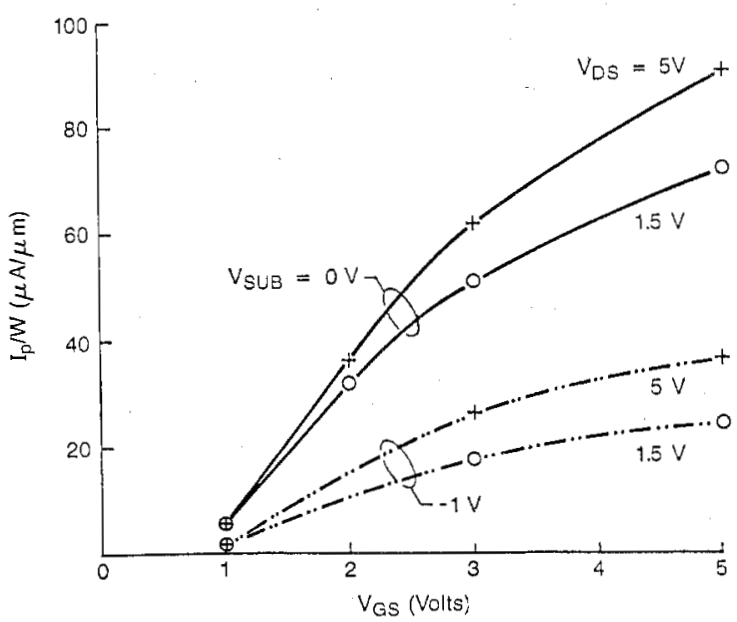

Fig. 11. Pinchoff current per unit channel width dependence on $V_{G S}$. PISCES simulated for the JMOSFET structure of Fig. 7. $V_{\text {SUB }}=0 \mathrm{~V}$.

simulated transfer function $\left(I_{p} / W\right)$ versus $V_{G S}$ is shown in Fig. 11, where $I_{p}$ is the pinchoff current of (3). A JFET short-channel effect is responsible for the output conductance in Fig. 10 and the variation of $I_{p}\left(V_{G S}\right)$ with $V_{D S}$ in 


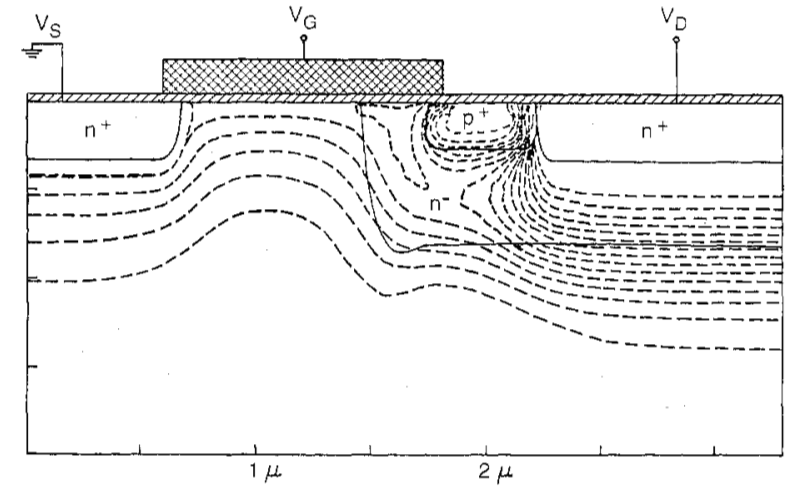

Fig. 12. PISCES simulated equipotential contours for the JMOSFET structure of Fig. 7. $V_{D S}=V_{G S}=5 \mathrm{~V}$. MOSFET is ON and JFET is OFF at $V_{\mathrm{SUB}}=-2 \mathrm{~V}$.

Fig. 11. This effect is quite easily seen in Fig. 8 as the drain field encroaches under the entire length of the $\mathrm{p}^{+}$ JFET gate. Fig. 12 shows the same device under bias conditions that turn the JMOSFET off through the application of substrate bias, while the MOSFET surface is strongly inverted. In the case illustrated, $V_{G S}=V_{D S}=5 \mathrm{~V}$ and $\left(V_{\text {SUB }}-V_{D_{i}}\right) \leq V_{T j}$, i.e., the drain JFET region is ofF and the MOSFET is ON. Thus, it is possible to turn off all JMOSFET's on a chip through appropriate substrate bias.

These device simulations have demonstrated the basic operation of the device. A variety of such simulations were used to suggest structural variations to optimize device performance. Control over the encroachment of high fields under the gate of the MOSFET can be achieved through proper design of the LDD region by adjusting the pinchoff voltage of the JFET region $V_{p}$ to maximize device current drive while keeping short-channel effects and hot-carrier injection into the gate oxide under tolerable limits.

\section{Device Fabrication}

The fabrication process used is a standard $2-\mu \mathrm{m}$ n-MOS process using LOCOS isolation, a $400-\AA$ gate oxide, and $\mathrm{n}^{+}$polysilicon gates. The starting material was $\langle 100\rangle$, $20-25-\Omega \cdot \mathrm{cm}$ boron-doped silicon. A $900-\AA \mathrm{Si}_{3} \mathrm{~N}_{4}$ on $400-\AA \mathrm{SiO}_{2}$ mask was used during the local oxidation. The boron field implant dose was $1.5 \times 10^{13} \mathrm{~cm}^{2}$ at 120 $\mathrm{keV}$. The field oxidation was done in steam at $1000^{\circ} \mathrm{C}$ for $200 \mathrm{~min}$.

Both conventional n-MOS devices and LDD n-MOS devices with five different variations in the source-drain regions were fabricated side by side, to test experimentally the JMOS device alongside the other better known LDD-MOSFET's. The major JMOS fabrication steps are shown in Fig. 13. By suitable combinations of the masked implants, all drain structures, including symmetrical JMOS and larger geometry JFET's, were fabricated side by side on the same chip. The asymmetric JMOS structure of Fig. 3 can be fabricated with only one extra masking step in addition to the conventional NMOS process if one were to choose an LDD-type source structure and a drain JFET structure. Lightly doped source structures should
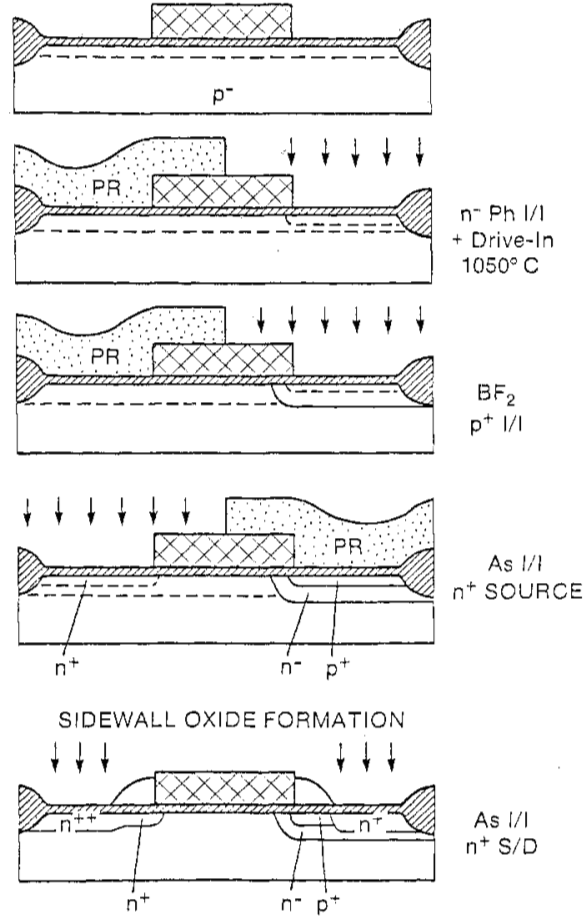

Fig. 13. Process sequence for JMOS fabrication.

either be doped above $5 \times 10^{18} \mathrm{~cm}^{-3}$ or be avoided altogether if transconductance reduction due to series source resistance [59]-[62] is to be kept low. Lighter doping levels are necessary on the drain, however, if one seeks to reduce the drain high field problem. In this work, three different $\mathrm{n}^{-}$phosphorus implant doses were used. Simulated surface concentrations for the $\mathrm{n}^{-}$region were $8 \times$ $10^{17} \mathrm{~cm}^{-3}$ for a low- $V_{p}$ JFET, $2 \times 10^{18} \mathrm{~cm}^{-3}$, and $3 \times$ $10^{18} \mathrm{~cm}^{-3}$ for higher $V_{p}$ JFET's, after a $1050^{\circ} \mathrm{C} 60-\mathrm{min}$ drive-in of the phosphorus implant. A shallow $100-\mathrm{keV}$ $\mathrm{p}^{+} \mathrm{BF}_{2}$ implant followed to form the substrate-connected JFET gate on the JMOS devices. The $1050^{\circ} \mathrm{C}$ anneal assured sufficient lateral diffusion of the $\mathrm{n}^{-}$implant to guarantee merging of the surface MOSFET channel and the JFET channel after the $\mathrm{p}^{+}$and $\mathrm{n}^{+}$implant anneals that followed. LDD region definition was done with a conventional sidewall spacer technology [63]-[64] by depositing 8000 - $\AA$ LPCVD oxide, followed by a $900^{\circ} \mathrm{C} / 30 \mathrm{~min}$ oxide densification and oxide plasma etch. Final sidewall oxide spacer widths of 4100 to $4600 \AA$ were obtained. Subsequently, a conventional $\mathrm{n}^{+}$As S/D implant and a $900^{\circ} \mathrm{C} / 30 \mathrm{~min}$ anneal followed. SUPREM-III simulated profiles after all anneals for the high- $V_{p}$ and low- $V_{p}$ JFET designs, as well as for the $\mathrm{n}^{+}$As drain profile are shown in Fig. 14. Final MOSFET channel region boron surface concentration was $1.3 \times 10^{16} \mathrm{~cm}^{-3}$. Table II summarizes the relevant parameters for the two JMOS designs to be mentioned.

\section{A. I-V Characteristics}

\section{Experimental Results}

Fig. 15 shows the drain current versus $V_{G S}$ characteristics for the low- $V_{p}$ JMOS device at $V_{D S}=0.1 \mathrm{~V}$, in 


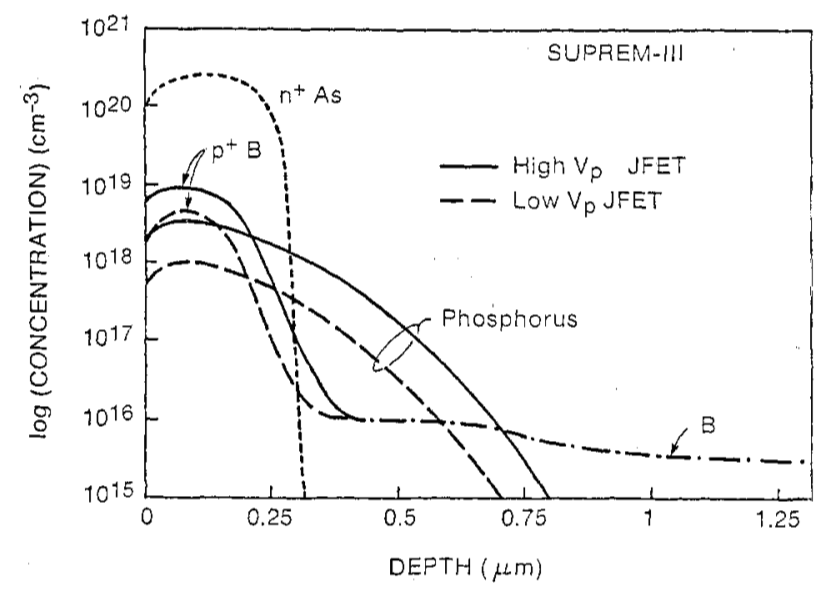

Fig. 14. SUPREM simulated impurity profiles for both JFET high- $V_{p}$ and low $-V_{p}$ designs.

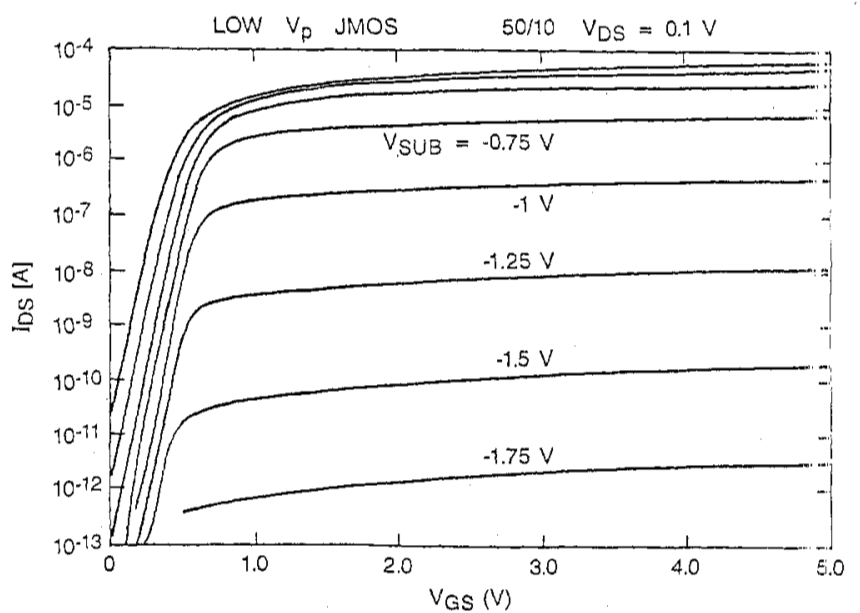

Fig. 15. Measured subthreshold characteristics for the low $-V_{p}$ JMOS $7 E T$. $W=50 \mu \mathrm{m}, L=10 \mu \mathrm{m}, V_{D S}=0.1 \mathrm{~V}, V_{\text {SUB }}$ steps of $-0.25 \mathrm{~V}$ fr $\supset \mathrm{m} 0$ to $-2 \mathrm{~V}$.

TABLE II

\begin{tabular}{|c|c|c|c|}
\hline \multicolumn{4}{|c|}{ PROCESS PARAMETERS } \\
\hline$P \overline{A R A M E T E R}$ & Eow $V_{p}$ Proc & igh $\overline{V_{p}}$ Process & Unit \\
\hline$N^{-}$Phosphorous Dose & $2 \times 10^{13}$ & $7.5 \times 10^{13}$ & $\mathrm{~cm}^{-2}$ \\
\hline Phosphorous surface conc. $\left(N_{S}\right)$ & $8 \times 10^{17}$ & $3 \times 10^{18}$ & $\mathrm{~cm}^{-3}$ \\
\hline$p^{+} \overline{B F}_{2}$ Dose & $6 \times 10^{13}$ & $2.2 \times 10^{14}$ & $\mathrm{~cm}^{-2}$ \\
\hline$N^{-}$sheet resistance $\left(\rho_{s}\right)$ & 850 & 410 & $\Omega / 0$ \\
\hline Pinched $\bar{N}^{-} p_{s}$ & 5.8 & 1.2 & $k \Omega / \square$ \\
\hline Oxide thickness $\left(t_{o x}\right)$ & 400 & $\overline{400}$ & $A$ \\
\hline Sidewall width $\left(L_{s w}\right)$ & 0.4 & 0.4 & $\mu \mathrm{m}$ \\
\hline
\end{tabular}

which both the JFET subthreshold and the MOS ZET subthreshold regimes are illustrated. The drain curren: exhibits the usual exponential turn-on [65] in the MOS $E \mathrm{ET}$ subthreshold regime. However, due to the drain JEET gating action, the drain current can be turned off by setting $V_{\text {SUB }}<V_{T_{J}}$. For this low $-V_{p}$ design $V_{T_{J}}=-\left(\left|V_{\text {, }}\right|-\right.$ $\left.\phi_{b i}\right)=-0.8 \mathrm{~V}$. The long-channel zero-backgate bias MOSFET threshold voltage is $0.32 \mathrm{~V}$, as extracted $\mathrm{b} /$ the TECAP2 [66] fitting of the conventional device lines 1 region $I_{D S}-V_{G S}$ characteristics at several substrate bitses. Fully extracted conventional MOSFET parameter are shown in Table I.

A $W=50 \mu \mathrm{m}, L=2 \mu \mathrm{m}$ JMOS device is compar $2 \mathrm{~d}$ to

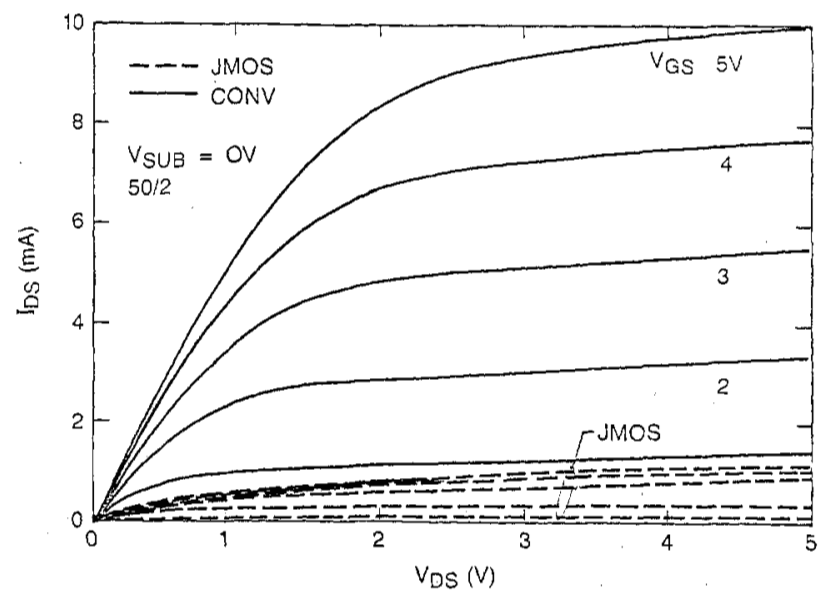

Fig. 16. Comparison of measured $I_{D S}$ versus $V_{D S}$ characteristics for the low- $V_{p}$ JMOSFET and conventional device. Both devices have the same drawn $W=50 \mu \mathrm{m}, L=2 \mu \mathrm{m}$.

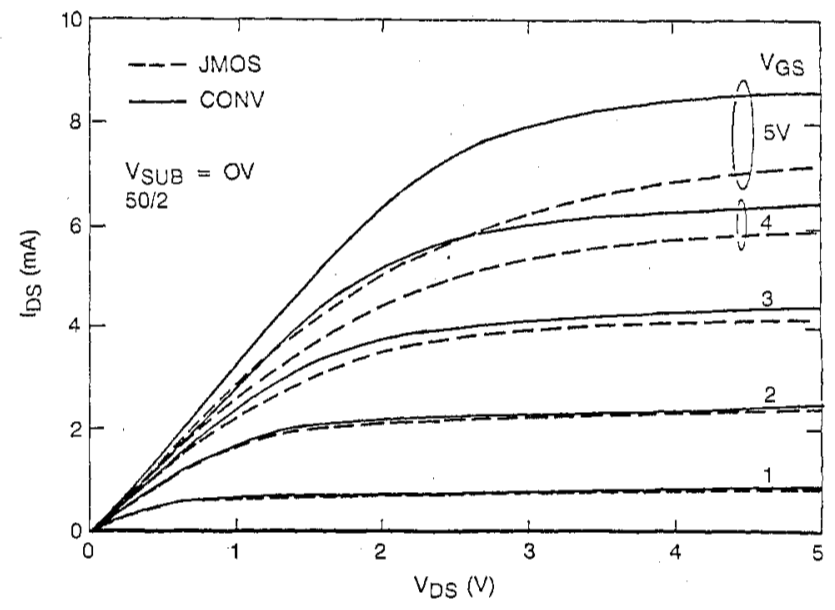

Fig. 17. Comparison of measured $I_{D S}$ versus $V_{D S}$ characteristics for a higher $V_{p}$ JMOSFET and conventional device. Both devices have the same drawn $W=50 \mu \mathrm{m}, L=2 \mu \mathrm{m}$.

a conventional MOSFET of the same drawn gate length in Fig. 16. The JMOS effective channel length is $\approx 0.2$ $\mu \mathrm{m}$ shorter than its conventional counterpart on the same chip. At large $V_{G S}$ the value of $I_{p}$ given by (3) saturates to a value $I_{p_{\max }}$ experimentally determined for devices with $L_{\text {gate }}=2 \mu \mathrm{m}$. This saturated value of the JMOS $I_{D S}$ for $V_{\text {SUB }}=0 \mathrm{~V}, V_{G S}=V_{D S}=5 \mathrm{~V}$ is $I_{p}=24 \mu \mathrm{A} / \mu \mathrm{m}$, and it is practically independent of MOSFET intrinsic channel length or polysilicon gate bias so that the JFET acts as a current limiter in the device structure. This value compares reasonably well with the simulated value $I_{D S_{\text {sat }}}=37$ $\mu \mathrm{A} / \mu \mathrm{m}$ for a slightly narrower sidewall spacer, and hence a shorter JFET length. The degree of current limiting by the JFET in this low- $V_{p}$ design is more than what would be desired in an actual VLSI application but its characteristics are shown here to illustrate the JFET action as the two active devices are merged.

The $I_{D S^{-}} V_{D S}$ characteristics of JMOSFET's with higher $V_{p}$ are compared to their conventional counterparts on the same chip in Figs. 17 and 18. These JMOSFET's have $I_{p \max }=200-$ and $320-\mu \mathrm{A} / \mu \mathrm{m}$ width, respectively. $I_{p \max }$ for 


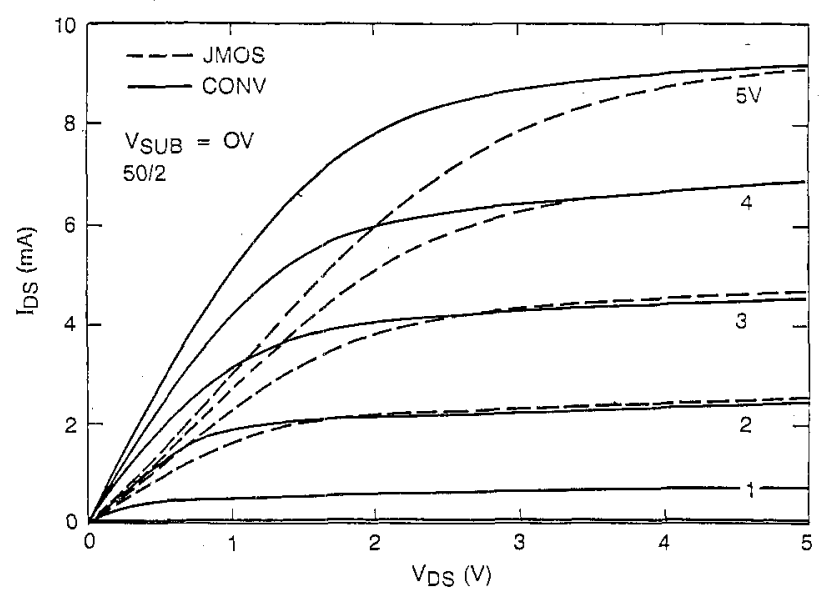

Fig. 18. Comparison of measured $I_{D S}$ versus $V_{D S}$ characteristics for the high- $V_{p}$ JMOSFET and conventional device. Both devices have the same drawn $W=50 \mu \mathrm{m}, L=2 \mu \mathrm{m}$.

the high- $V_{p}$ design of Fig. 18 is larger than the 5-V current drive capability of our conventional enhancement n-MOS devices built with a $400-\AA$ gate oxide $2-\mu \mathrm{m}$ technology. Hence, for large $V_{D S}$-bias short-channel MOSFET, the JMOSFET saturation current limit is given by velocity saturation of the MOSFET inversion carriers, according to (2). In the high- $V_{p}$ case, as shown in Fig. 18, the $I_{D S_{\text {sat }}}$ values are the same for both conventional and JMOSFET devices. In this case the operation of the drain JFET is in its linear region, and the device acts as a simple buried LDD. This has the effect of increasing the linear region ON resistance of the JMOSFET. Drain series resistance for this case was extracted to be $10 \mathrm{k} \Omega \cdot \mu \mathrm{m}$ in excess of the conventional transistor series resistance by using the measurement procedure of [67]. Based on measured sheet resistivity data for large geometry $\mathrm{n}^{-}$pinched resistors, one concludes that the $\mathrm{n}^{-}$buried LDD contribution to the series drain resistance does not account for such a large series resistance increase. We believe that a sizable contribution to this ON resistance of the high- $V_{p}$ JMOSFET comes from the contact resistance of the $\mathrm{Al}(1$-percent $\mathrm{Si}$ ) metallization to the $\mathrm{n}^{+}$drain diffused layer which is compensated by the high dose $\left(2.2 \times 10^{14} \mathrm{~cm}^{-2}\right) \mathrm{p}^{+}$JFET gate implant. Further improvements of this device structure are necessary to address several detrimental effects of including a shallow $\mathrm{p}^{+}$implant into the drain $\mathrm{n}^{-}$region: first, the low breakdown voltage of the $\mathrm{p}^{+}$substrate $-\mathrm{n}^{+}$ drain junction; second, increased on resistance due to impurity compensation of the surface $\mathrm{n}^{-}$region; and third, the effect of the compensated $p^{+}$layer on the contact resistance of the metal to $\mathrm{n}^{+}$region. These limitations can be overcome by more optimum design of the doping profiles in the drain region.

The $1050^{\circ} \mathrm{C}^{-}$drive-in step results in a fairly deep $\mathrm{n}^{-}$ junction in the high- $V_{p}$ case, $\approx 0.7 \mu \mathrm{m}$ according to the simulation results in Fig. 14. Also, considerable diffusion of the channel implants for $V_{T}$ adjustment and punchthrough suppression occurs. Scaling suggests that the $S /$ $\mathrm{D}$ junction depths should be kept as shallow as technologically feasible. A JMOS device optimized for technol-

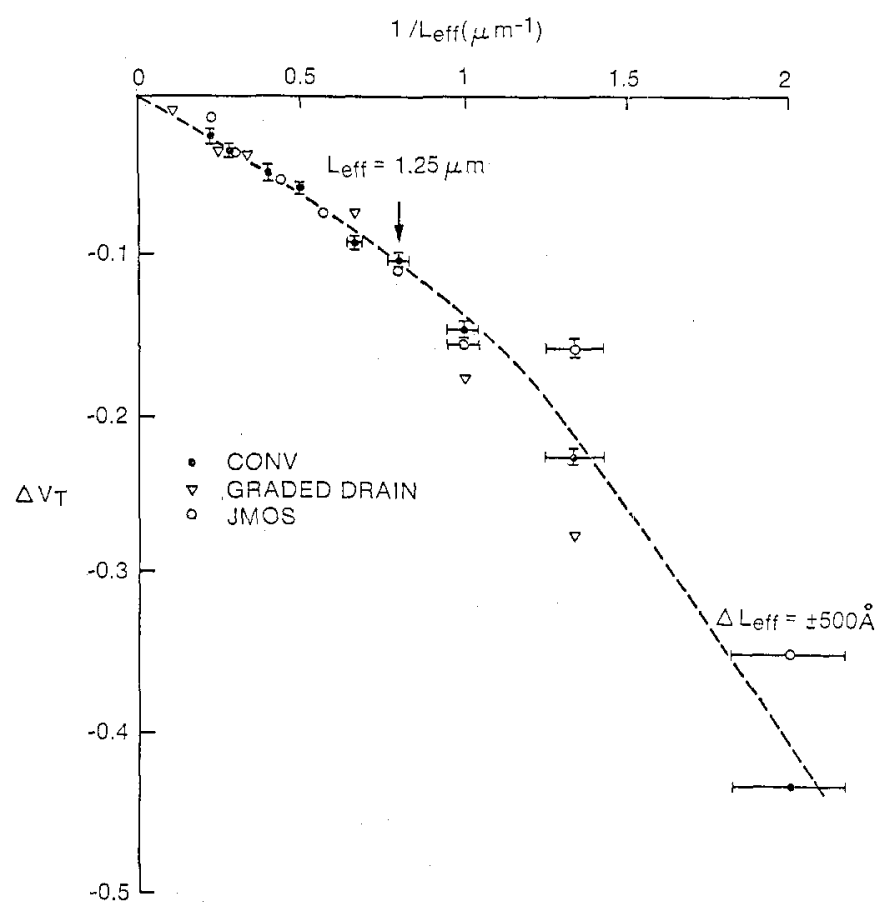

Fig. 19. Linear region threshold shift as a function of effective channel length. $V_{T}$ extrapolation measurement at $V_{D S}=100 \mathrm{mV}$.

ogies with $L_{\mathrm{eff}}<1 \mu \mathrm{m}$ would have to use shallower junctions. The threshold voltage shift in the short channel regime should in turn be controlled by an appropriate choice of $t_{\mathrm{ox}}$ and punchthrough suppression implant dose. For the technology choices in this experiment, all devices had a linear region short-channel $V_{T}$ shift of less than 100 $\mathrm{mV}$ down to $L_{\mathrm{eff}}=1.25 \mu \mathrm{m}$ as shown in Fig. 19 for conventional $(\bigcirc)$, high- $V_{p}(\bigcirc)$ and graded $S / D(\triangle)$ devices. The $V_{T}$ measurement used for Fig. 19 assumes that the threshold voltage is given by the linear region $\left(V_{D S}=0.1\right.$ V) extrapolation of the $I_{D S}-V_{G S}$ curves at the maximum value of transconductance.

\section{B. Substrate Current}

In Fig. 20 the substrate current versus $V_{G S}^{\prime}$ characteristics of both a conventional and a low- $V_{p}$ MOSFET (same device as Fig. 16) are compared for devices with the same drawn $W=50 \mu \mathrm{m}, L=1.5 \mu \mathrm{m}$. The usual substrate current characteristics [68] are observed for the conventional MOSFET. Its bell-like shape indicates that the substrate current is mostly due to holes generated by impact ionization occurring as carriers traverse the high field region under the gate in the drain end of the device. The JMOSFET substrate current is mostly independent of gate voltage; it is not triggered by channel current; and, it is more than two orders of magnitude lower than the peak value of the conventional device. Except for the bias regime in which the conventional MOSFET is well into its linear mode of operation $\left(V_{G S}>V_{D S}\right)$, i.e., the inversion layer extends from source to drain $\mathrm{n}^{+}$regions and decreases the longitudinal field strength in the drain end of the channel, the JMOS $I_{\mathrm{SUB}}$ is less than the conventional MOSFET impact ionization substrate current. 


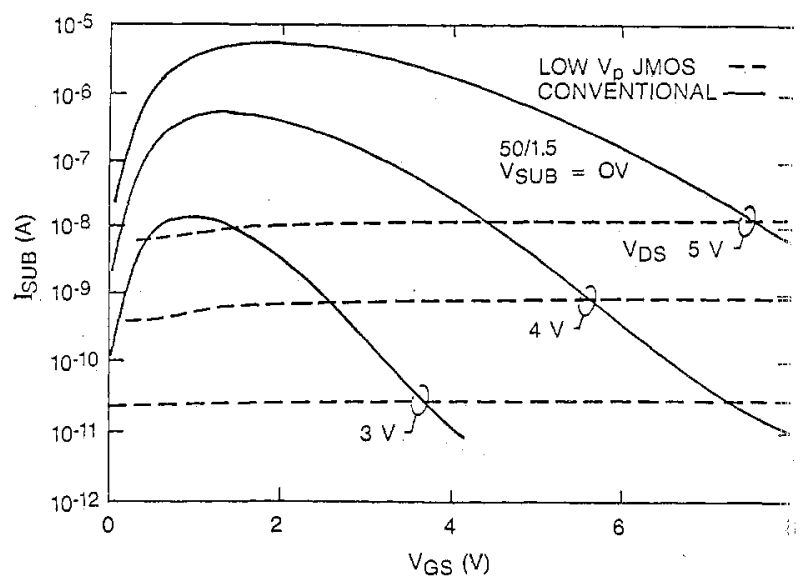

Fig. 20. Substrate current versus $V_{G S}$ comparison for conventional solid line) and low $-V_{p}$ JMOS (dashed) at $V_{D S}=3,4,5 \mathrm{~V}$. Drawn $W=50$ $\mu \mathrm{m}, L=1.5 \mu \mathrm{m}$ for both devices. Low $-V_{p} L_{\text {eff }}=0.8 \mu \mathrm{m}$, conven ional $L_{\mathrm{eff}}=1.0 \mu \mathrm{m}$.

Drain diodes built on the same chip with different $\mathrm{s}$ rea/ perimeter ratio confirmed that the JMOS substrate culyent shown in Fig. 20 is mostly $\mathrm{p}^{+}-\mathrm{n}^{+}$sidewall diode leakage. This Zener-like drain-substrate leakage is fairly independent of channel current, hence independent of polysilicon gate length and MOSFET gate bias, and it scales with device width to a typical room temperature value of -300 $\mathrm{pA} / \mu \mathrm{m}$ at $V_{D S U B}=5 \mathrm{~V}$. In JMOS designs with higher $\mathrm{n}^{-}$ and $\mathrm{p}^{+}$doping densities, the Zener leakage under the ame conditions can increase by orders of magnitude when tunneling becomes important, to a typical maximum of -500 $\mathrm{nA} / \mu \mathrm{m}$ when both sides of the sidewall junction wer: degenerately doped. High sensitivity to $\mathrm{p}^{+}$doping levels are expected for shallow $\mathrm{n}^{+}(\mathrm{As}) / \mathrm{p}^{+}$(boron) junctions witl $\mathrm{p}^{+}$doping levels above $10^{18} \mathrm{~cm}^{-3}$ [69]. This suggests that an optimum JMOS design must pay careful attention th the $\mathrm{p}^{+}$doping profile in particular, if substrate current is to be minimized.

\section{Gate Current}

Very sensitive gate current measurements were done at the wafer level utilizing a floating-gate-induced drair current relaxation technique demonstrated in [70]. Resolution below $10^{-16} \mathrm{~A}$ was possible with this technique.

Gate current comparisons presented herein are for devices built side by side on the same chip, since small structural or doping variations can lead to invalid comparisons. Fig. 21 compares the gate current measured as function of $V_{G S}$ for a conventional, and for the low- $V_{p}$ JMOSFET of Fig. 16 on the same chip. The former s lows the characteristic bell-shaped peak that has been attributed to lucky channel hot electrons (CHE) [7], [71], 'while the JMOSFET gate current is below the noise level in the measuring apparatus. This extreme reduction of the gate current in the low- $V_{p}$ JMOS device can be attributed to the reduction of the internal drain voltage $V_{D_{i}}$ on the MOSFET due to the presence of the series JFET, even though the external $V_{D S}$ is $7 \mathrm{~V}$ in this measurement. Fig. 21 also presents the gate current of the graded S/D device

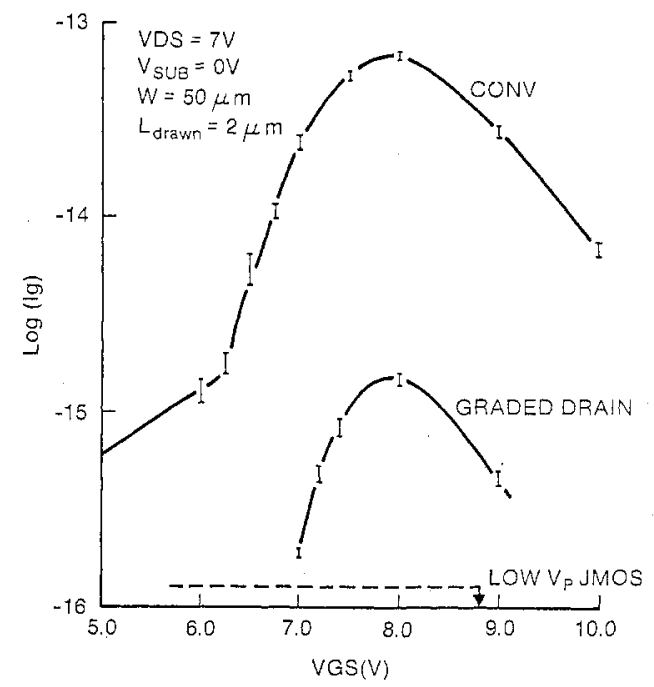

Fig. 21. Gate current versus $V_{G S}$ comparison for conventional and low- $V_{p}$ devices. Both have drawn $W=50 \mu \mathrm{m}, L=2 \mu \mathrm{m}$. Conventional $L_{\mathrm{eff}}=$ $1.5 \mu \mathrm{m}$, JMOS $L_{\mathrm{eff}}=1.3 \mu \mathrm{m}$. $V_{D S}=7 \mathrm{~V}, V_{\mathrm{SUB}}=0 \mathrm{~V}$. Graded $\mathrm{S} / \mathrm{D}$ device with $L_{\mathrm{eff}}=1.1 \mu \mathrm{m}$ is also shown.

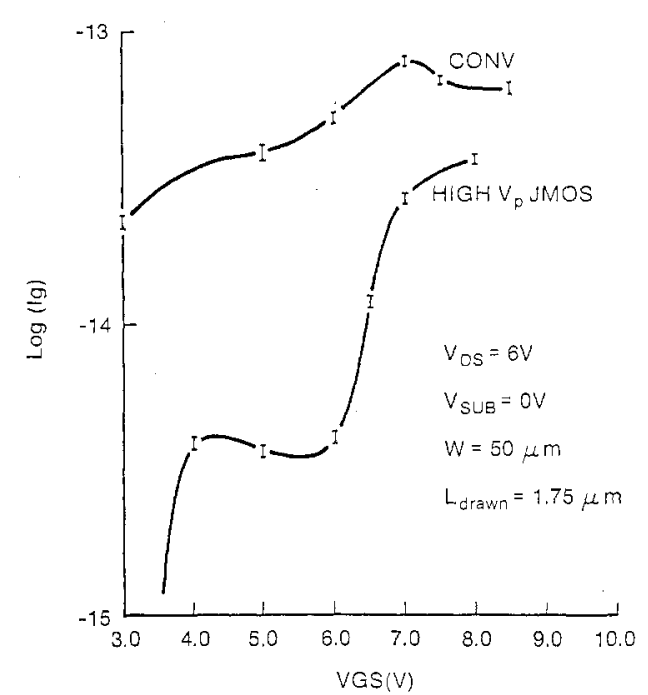

Fig. 22. Gate current versus $V_{G S}$ comparison for conventional and high- $V_{p}$ devices. Both have drawn $W=50 \mu \mathrm{m}, L=1.75 \mu \mathrm{m}$. Conventional $L_{\text {eff }}$ $=1.2 \mu \mathrm{m}$, JMOS $L_{\mathrm{eff}}=1.0 \mu \mathrm{m} . V_{D S}=6 \mathrm{~V}, V_{\mathrm{SUB}}=0 \mathrm{~V}$.

on the same chip, which gives an indication of impact ionization reduction due to drain grading alone. The reduction of the JMOSFET gate current is clearly due to a reduction of $V_{D_{i}}$, in addition to junction grading. This is consistent with the $I-V$ characteristics of Fig. 16 and the substrate current characteristics of Fig. 20, which indicated that the JFET drain supported most of the drain bias and that impact ionization was negligible under the gate of the low- $V_{p}$ JMOSFET, respectively.

Fig. 22 presents the gate current comparison for devices on the same chip of a high- $V_{p}$ wafer, measured at $V_{D S}=6 \mathrm{~V}$. Effective channel lengths are $1.25 \mu \mathrm{m}$ for the conventional MOSFET, and $1.0 \mu \mathrm{m}$ for the JMOSFET. In the CHE $I_{G}$ peak (at $V_{G S}-V_{D S}$ ) the reduction provided by the high- $V_{p}$ JMOS is relatively small. At lower gate voltages, however, where impact ionization is more in- 


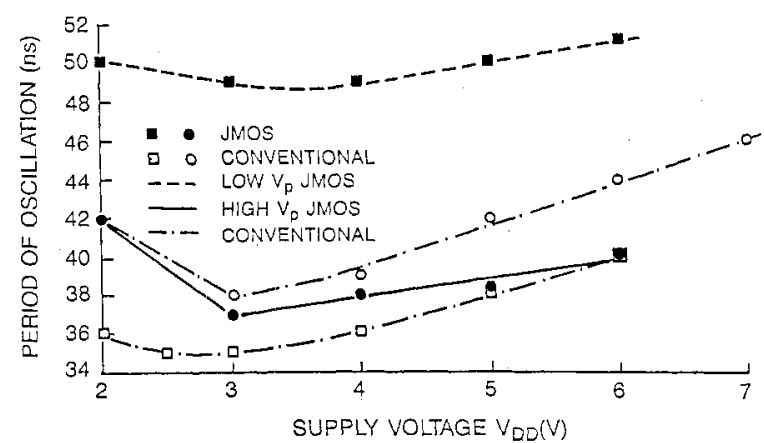

Fig. 23. E/D ring-oscillator period of oscillation versus supply voltage. Boxes $(\square \mathbf{\square})$ indicate the low $-V_{p}$ experiment. Circles $(O \bullet)$ indicate the high- $V_{p}$ experiment

tense in conventional devices there is about one order of magnitude reduction in $I_{G}$ measured in the JMOS structure. It is clear from Figs. 21 and 22 that as the JFET pinchoff voltage is reduced, the JFET increasingly limits the overall device current but also increasingly improves the gate current due to hot carriers.

\section{Speed Performance}

Ring oscillators with fan-in $=$ fan-out $=1$ were built to benchmark on the same chip the speed performance of the two JMOSFET device designs against conventional designs. The 21 inverter stages were of the n-channel enhancement/depletion (E/D) type. Depletion and enhancement-mode JMOSFET's were used in the JMOS inverter stages. All ring oscillators had the same drawn geometries: $(12 \mu \mathrm{m} / 3 \mu \mathrm{m}$ drivers, $8 \mu \mathrm{m} / 8 \mu \mathrm{m}$ loads $)$. Fig. 23 shows the oscillation period as a function of the supply voltage for two wafers. The speed performance of the low$V_{p}$ design (dashed line) is much degraded as compared to the conventional device speed $(\square)$. This performance degradation is expected since the drive capability of the JMOS inverter stage is severely limited by the low- $V_{p}$ drain JFET as shown in Fig. 16.

The high- $V_{p}$ JMOS ring oscillator had a speed (solid line) comparable to the conventional design on the same chip (O). The slight speed-up for this JMOSFET design is solely attributable to the smaller $L_{\text {eff }}$ of the transistors, $(\approx 0.25 \mu \mathrm{m}$ shorter $)$, and it is within the wafer to wafer variation of the speed performance of the conventional devices. Usually in E/D circuits the average pull-up output current increases sublinearly with supply voltage. For this reason, the larger logic swing at larger supply voltages results in a slow down of the ring oscillator speed as $V_{D D}$ increases, as shown in Fig. 23.

The introduction of the $\mathrm{p}^{+}$region in the JMOSFET drain has the positive effect of reducing the gate to $\mathrm{n}^{+}$ drain feedback capacitance $\left(C_{G D}\right)$ at the expense of the increasing both drain to substrate junction capacitance $\left(C_{D S U B}\right)$ and gate to $\mathrm{p}^{+}$overlap/fringing capacitance $\left(C_{G S U B}\right)$.

\section{Discussion}

The JMOS structures studied have demonstrated the basic advantages of this device design. First, the maxi- mum effective MOSFET drain bias can be set by device design, independently of the maximum externally applied drain and gate bias that can be set at effectively higher voltages. This property is advantageous in view of the pressing need for voltage reduction in conventional submicrometer MOSFET's brought on by hot-carrier effects. Second, the JMOSFET lightly doped drain region can be engineered without the usual reliability constraint imposed on conventional LDDFET's due to hot-carrier injection under the sidewall; reliable LDDFET's require $N_{S}$ $>10^{18} \mathrm{~cm}^{-3}$ in the $\mathrm{n}^{-}$region, while the buried $\mathrm{n}^{-}$region in the JMOSFET can be more lightly doped to meet the designer's choice for JFET $V_{p}$. Third, the advantages in channel longitudinal field reduction due to drain junction grading that are common to all LDD-like structures previously studied, are also present in the JMOSFET with the additional advantage of having the channel current driven away from the $\mathrm{SiO}_{2}$ interface in the high-field drain region. All three features combined allow further minimization of charge injection, trapping, and instabilities associated with the gate oxide. Based on the proven correlation between gate and substrate currents and device reliability found in both conventional and LDD-like devices, we expect submicrometer JMOSFET's to have good endurance under hot-carrier stress.

Our implementations of the JMOSFET have pointed to areas that merit further improvement. First, the breakdown voltage of the sidewall $\mathrm{n}^{+}-\mathrm{p}^{+}$junction at $6.5 \mathrm{~V}$ and the associated junction leakage seen at $5 \mathrm{~V}$ render the drain-to-substrate leakage unacceptable for dynamic circuit applications. The use of a phosphorus $\mathrm{n}^{+}$region selfaligned to the sidewall oxide or a slight $(\approx 0.2 \mu \mathrm{m})$ anisotropic silicon etch-back prior to arsenic $\mathrm{n}^{+}$implant in order to grade or eliminate the $n^{+}-p^{+}$sidewall junction are possible technology implementations that can overcome this shortcoming. Second, a symmetrical JMOSFET suffers from a further effective transconductance decrease due to an increase in series source resistance $\left(R_{S}\right)$, since

$$
g_{m_{\mathrm{sym}}}=\frac{g_{m_{J}}}{1+g_{m J} R_{S}}
$$

where $g_{m J}$ and $g_{m_{\mathrm{sym}}}$ are the JMOSFET and symmetrical JMOSFET effective transconductances, respectively. This likely means that an extra mask must be used to eliminate the $\mathrm{p}^{+}$region on the source side. Third, process complexity and control are relevant issues in the comparison of the JMOSFET and more conventional clesigns. The presence of a self-aligned active device under the oxide spacer that controls the current drive of the JMOSFET makes oxide spacer process control even more necessary. The addition of at least one extra masking step with worst case alignment tolerance of $L_{\mathrm{gate}} / 2$ is one additional drawback of the JMOSFET in its asymmetric implementation.

\section{CONCLUSIONS}

The JMOSFET, a modified LDD device structure has been proposed, designed, modeled, and experimentally 
demonstrated. It provides designers with tradeoffs in performance somewhat different than LDD devices previously reported. The JMOS device can be optimized for a given technology choice of minimum effective chan rel length, oxide thickness, and supply voltage. It overconies some of the reliability problems of LDD devices with $\mathrm{p}$ a ak doping densities below $1 \times 10^{18} \mathrm{~cm}^{-3}$ related to injection into the sidewall oxide. By keeping the longitudinal $\mathrm{E}$ field peak away from the $\mathrm{SiO}_{2}-\mathrm{Si}$ interface, the JMC 3 FET structure minimizes hot-carrier injection into the oxide-as made evident through gate and substrate curringt characteristics-and should minimize also the reliability problems associated with that injection. The particular experimental devices described here show that the JM S can be designed to virtually eliminate gate current, at a substantial cost in performance, or to moderately redice gate current at a minimal cost in performance, compaled to conventional devices. Our results suggest that with proper optimization of the drain JFET this new structive can perform well in VLSI applications, while maintaining its hot-carrier-resistant properties in submicron $5-\mathrm{V}$ si.jpply circuits. Further work is needed, however, to de nonstrate quantitatively the trade-offs that exist in circuit performance and reliability. As has been the case with all LDD-like structures, improved device reliability has been achieved at some expense in performance. However, the advantages of keeping 5-V operation in micron sized devices can outweigh this performance loss.

\section{ACKNOWLEDGMENT}

We acknowledge the students and staff of the Integrated Circuits Laboratory for their support in simulation, wa er fabrication, and testing.

\section{REFERENCES}

[1] R. H. Dennard, F. H. Gaensslen, H.-N. Yu, V. L. Rideout, E. Bassous, and A. R. LeBlanc, "Design of ion-implanted MOSFET's vi ith very small physical dimensions," IEEE J. Solid-State Circuits, val. SC-9, pp. 256-267, Oct. 1974.

[2] J. R. Brews, W. Fichtner, E. H. Nicollian, and S. M. Sze, "Gereralized guide for MOSFET miniaturization," IEEE Electron Der ice Lett., vol. EDL-1, pp. 2-4, Jan. 1980.

[3] P. Chaterjee, W. Hunter, T. Holloway, and Y. Lin, "The impacl of scaling laws on the choice of n-channel or p-channel for MOS VLS ," IEEE Electron Device Lett,, vol. EDL-1, pp. 220-223, Oct. 198c.

[4] G. Baccarani, M. R. Wordeman, and R. H. Dennard, "Generali:ed scaling theory and its applications to a $\frac{1}{4}$ micrometer MOSFET deisgn," IEEE Trans. Electron Devices, vol. ED-31, pp. 452-452, Apr. 1984.

[5] S. A. Abbas, and R. C. Dockerty, "Hot-carrier instability in $\mid \mathrm{G}$ FET's," Appl. Phys. Lett., vol. 27, pp. 147-148, Aug. 1975.

[6] P. E. Cottrell, R. R. Troutman, and T. H. Ning, "Hot-electron en ission in n-channel IGFET's," IEEE J. Solid-State Circuits, vol. \& C14, pp. 442-455, Apr. 1979.

[7] T. H. Ning, P. W. Cook, R. H. Dennard, C. M. Osburn, S. E. Sch 1ister, and H. N. Yu, "1 1 m MOSFET VLSI technology: Part IV-Hot electron design constraints," IEEE Trans. Electron Devices, vol. ED26, pp. 346-352, Apr. 1979.

[8] R. B. Fair and R. C. Sun, "Threshold-voltage instability in MO $18-$ FET's due to channel hot-hole emission," IEEE Trans. Electron i?pvices, vol. ED-28, pp. 83-93, Jan. 1981.

[9] A. E. Schmitz and J. Y. Chen, "Design, modeling, and fabricat on of subhalf-micrometer CMOS transistors," IEEE Trans. Electron ?? vices, vol. ED-33, pp. 148-153, Jan. 1986.
[10] K. Saito, T. Morase, S. Sato, and U. Harada, "A new short channel MOSFET with lightly doped drain," Denshi Tsushin Rengo Taikai, p. 220, Apr. 1978 (in Japanese).

[11] K. Ohta, K. Yamada, K. Shimizu, and Yasuo Tarui, "A quadruply self-aligned MOS (QSA MOS): A new short channel high speed high density MOSFET for VLSI," in IEDM Tech. Dig., pp. 581-584, 1979.

[12] K. Ohta, K. Yamada, M. Saitoh, K. Shimizu, and Y. Tarui, "Quadruply self-aligned MOS (QSA MOS) - A new short-channel high-speed high-density MOSFET for VLSI," IEEE Trans. Electron Devices, vol. ED-27, pp. 1352-1358, Aug. 1980.

[13] S. Ogura, P. J. Tsang, W. W. Walker, D. L. Critchlow, and J. F. Shepard, "Design characteristics of the lightly doped drain-source (LDD) insulated gate field-effect transistor," IEEE Trans. Electron Devices, vol. ED-27, pp. 1359-1367, Aug. 1980.

[14] - "Elimination of hot electron gate current by the lightly doped drain-source structure," in IEDM Tech. Dig., p. 651, 1981.

[15] S. Hsia, R. Fatemi, T. C. Teng, S. Deornellas, and S. C. Sun, "Polysilicon oxidation self-aligned MOS (POSA MOS)-A new self-aligned double source/drain ion implantation technique for VLSI," IEEE Electron Device Lett., vol. EDL-3, pp. 40-42, Feb. 1982.

[16] P. J. Tsang, S. Ogura, W. Walker, J. Shepard, and D. Critchlow, "Fabrication of high-performance LDDFET's with oxide sidewallspacer technology," IEEE Trans. Electron Devices, vol. ED-29, pp. 590-595, Apr. 1982.

[17] E. Takeda, H. Kume, T. Toyabe, and S. Asai, "Submicrometer MOSFET structure for minimizing hot-carrier generation," IEEE Trans. Electron Devices, vol. ED-29, pp. 611-618, Apr. 1982.

[18] S. Ogura, C. F. Codella, N. Rovedo, J. F. Shepard, and J. Riseman, "A half micron MOSFET using double implanted LDD," in IEDM Tech. Dig., pp. 718-721, 1982.

[19] S. Ratham, H. Bahramian, D. Laurent, and Y.-P. Han, "An optimized 0.5 micron LDD transistor," in IEDM Tech. Dig., pp. 237-241, 1983.

[20] Y. Matsumoto, T. Higuchi, S. Sawada, S. Shinozaki, and O. Ozawa, "Optimized and reliable LDD structure for $1 \mu \mathrm{m}$ NMOSFET based on substrate current analysis," in IEDM Tech. Dig., pp. 392-395, 1983.

[21] H. Sunami, K. Shimohigashi, and N. Hashimoto, "Characteristics of a buried-channel graded drain with punchthrough stopper (BGP) MOS device," IEEE Trans. Electron Devices, vol. ED-29, Apr. 1982

[22] S. Satoh, Y. Ohbayashi, K. Mizuguchi, M. Yoneda, and H. Abe, "Self-aligned graded-drain structure for short channel MOS transistor," in Symp. VLSI Technol. Dig. Tech. Papers, p. 38, 1982.

[23] M. L. Chen, B. C. Leung, A. G. F. Dingwall, and B. Lalevic, "Selfregistered gradually doped source drain extension short channel CMOS/SOS devices," IEEE Electron Device Lett., vol. EDL-3, pp. 387-390, Dec. 1982.

[24] E. Takeda, H, Kume, Y. Nakagome, T. Makino, A. Shimizu, and S. Asai, "An As-P $\left(\mathrm{n}^{+}-\mathrm{n}^{-}\right)$doubled diffused drain MOSFET for VLSI's,"' IEEE Trans. Electron Devices, vol. ED-30, pp. 652-657, June 1983; also, E. Takeda, H. Kume, Y. Nakagome, and S. Asai, "An As-P $\left(\mathrm{n}^{+} / \mathrm{n}^{\text {" })}\right.$ doubled diffused drain MOSFET for VLSI's," in Symp. VLSI Technol. Dig. Tech. Papers, p. 40, 1982.

[25] K. Balasubramanyam, M. J. Hargrove, H. I. Hanafi, M. S. Lin, D. Hoyniak, J. LaRue, and D. R. Thomas, "Characterization of As-P double diffused drain structure," in IEDM Tech. Dig., pp. 782-785, Dec. 1984

[26] S. Aur, P. Yang, P. Pattnaik, and P. K. Chatterjee, "Modeling of hot carrier effects for LDD MOSFET's," in Symp. VLSI Technol. Dig. Tech. Papers, pp. 112-113, 1985.

[27] Y. Tsunashima et al., "Metal-coated lightly-doped drain (MLD) MOSFET's for sub-micron VLSI's," in Symp. VLSI Technol. Dig. Tech. Papers, pp. 114-115, 1985.

[28] K. Yamaguchi, S. Takahashi, and H. Kodera, "Theoretical study of a channel-doped separate gate Si MOSFET (SG-MOSFET) by twodimensional computer simulation," IEEE Trans. Electron Devices, vol. ED-28, pp. 117-120, Jan. 1981.

[29] K. Yamagushi and S. Takahashi, "Submicron gate MOSFET's with channel-doped separate gate structure (SG-MOSFET's)," IEEE Trans. Electron Devices, vol. ED-28, pp. 888-890, July 1981.

[30] R. E. Howard et al., "Buried channel MOSFET's with gate lengths from $2.5 \mu \mathrm{m}$ to $700 \AA$," IEEE Electron Device Lett., vol. EDL-3, pp. $322-324$, Oct. 1982 .

[31] R. G. Swartz et al., "700 ^ gate length buried channel silicon MOSFET's," in IEDM Tech. Dig., pp. 642-645, 1982.

[32] L. D. Jackel et al., "CASFET: A MOSFET-JFET cascode device 
with ultralow gate capacitance," IEEE Trans. Electron Devices, vol. ED-31, pp. 1752-1757, Dec. 1984.

[33] F. C. Hsu and H. R. Grinolds, "Structure-enhanced MOSFET degradation due to hot-electron injection," IEEE Electron Device Lett. vol. EDL-5, pp. 71-74, Mar. 1984; also —, "Structure-dependent MOSFET degradation due to hot-electron injection," in IEDM Tech. Dig., (Late News), pp. 742-744, 1983

[34] F. -C. Hsu and K.-Y. Chiu, "Evaluation of LDD MOSFET's based on hot-electron-induced degradation," IEEE Electron Device Lett., vol. EDL-5, pp. 162-165, May 1984.

[35] Y. Toyoshima, H. Nihira, M. Wada, and K. Kanzaki, "Mechanism of hot electron induced degradation in LDD NMOS-FET, " in IEDM Tech. Dig., pp. 786-789, 1984

[36] H. Katto, K. Okuyama, S. Meguro, R. Nagai, and S. Ikeda, "Hot carrier degradation modes and optimization of LDD MOSFET's," in IEDM Tech. Dig., pp. 774-777, 1984.

[37] S. N. Shabde, F. Barman, and A. Bhattacharya, "Channel-length dependence of substrate current characteristic of LDD MOSFET's," IEEE Trans. Electron Devices, vol. ED-32, pp. 1885-1887, Sept 1985 .

[38] C. Werner, R. Kuhnert, and L. Risch, "Optimization of lightly doped drain MOSFET's using a new quasiballistic simulation tool," in IEDM Tech. Dig., pp. 770-773, 1984.

[39] K.-L. Chen, S. Saller, and R. Shah, "Some methods to reduce hot carrier effects," in Symp. VLSI Technol. Dig. Tech. Papers, pp. 102$103,1985$.

[40] H. Mikoshiba, T. Horiuchi, and K. Hamano, "Comparison of drain structures in n-channel MOSFET's," IEEE Trans. Electron Devices, vol. ED-33, pp. 140-144, Jan. 1986

[41] M. Kinugawa, M. Kakumu, S. Yokogawa, and K. Hashimoto, "Submicron MLDD NMOSFET's for 5 V operation,"'in Symp. VLSI Technol. Dig. Tech. Papers, pp. 116-117, 1985.

[42] Y. Toyoshima, N. Nihira, and K. Kanzaki, "Profiled lightly doped drain (PLDD) structure for high reliable NMOS-FET's," in Symp. VLSI Technol. Dig. Tech. Papers, pp. 118-119, 1985

[43] D. A. Baglee, C. Duvvury, M. C. Smayling, and M. P. Duane "Lightly doped drain transistors for advanced VLSI circuits,"' IEEE Trans. Electron Devices, vol. ED-32, pp. 896-902, May 1985.

[44] M. Koyanagi, H. Kaneko, and S. Shimizu, "Optimum design of $n^{+}$ $\mathrm{n}^{-}$double-diffused drain MOSFET to reduce hot-carrier emission," IEEE Trans. Electron Devices, vol. ED-32, pp. 562-570, Mar, 1985

[45] F. S. Lai, "An analytic model to estimate the avalanche breakdown voltage-improvement for LDD devices," Solid-State Electron., vol. 28 , pp. $959-965$, Oct. 1985

[46] F.-S. J. Lai and J. Y.-C. Sun, "An analytical one-dimensional model for lightly doped drain (LDD) MOSFET devices," IEEE Trans, Electron Devices, vol. ED-32, pp. 2803-2811, Dec. 1985.

[47] S. Bampi and J. D. Plummer, "Modified LDD device structures for VLSI," in IEDM Tech. Dig., pp. 234-237, 1985.

[48] M. Nakahara, Y. Hiruta, T. Noguchi, M. Yoshida, K. Maeguchi, and K. Kanzaki, "Relief of hot carrier constraint on submicron CMOS devices by use of a buried channel structure," in IEDM Tech. Dig., pp. $238-241,1985$.

[49] H. R. Grinolds, M. Kinugawa, and M. Kakumu, "Reliability and performance of submicron LDD MOSFET's with buried-As $\mathrm{n}^{-}$impurity profiles," in IEDM Tech. Dig., pp. 246-249, 1985

[50] W. Fichtner, J. A. Cooper, A. R. Tretola, and D. Kahng, "A novel buried-drain DMOSFET structure,"' IEEE Trans. Electron Devices, vol. ED-29, pp. 1785-1791, Nov. 1982; also, _ "A novel buried drain DMOSFET structure," in IEDM Tech. Dig., pp. 363-366, 1981.

[51] S. M. Sze, Physics of Semiconductor Devices. New York: WileyInterscience, 1969 , p. 348.

[52] C. H. Price, "Two-dimensional numerical simulation of semiconductor devices," Stanford Electronics Lab. Tech. Rep., May 1982.

[53] M. R. Pinto, C. S. Rafferty, and R. W. Dutton, "PISCESII: Poisson and continuity equation solver," Stanford Electronics Lab. Tech. Rep., Sept. 1984.

[54] C. P. Ho et al., "SUPREM-III-A program for integrated circuit process modeling and simulation," Stanford Electronics Lab. Tech. Rep. SEL84-001, July 1984.

[55] A. Schutz and C. Werner, "State-of-the-art of MOS modelling," in IEDM Tech. Dig., pp. 766-769, 1984

[56] Y. A. El-Mansy and A. R. Boothroyd, "A simple two-dimensional model for IGFET operation in the saturation region," IEEE Trans. Electron Devices, vol. ED-24, pp. 254-262, Mar. 1977.

[57] C. Hu, "Hot-electron effects in MOSFET's," in IEDM Tech. Dig., pp. 176-181, 1983.
[58] T. Y. Chan, P. K. Ko, and C. Hu, "Dependence of channel electric field on device scaling," IEEE Electron Device Lett., vol. EDL-6, pp. 551-553, Oct. 1985

[59] C. Duvvury et al., "Series resistance modeling for optimum design of LDD transistors," in IEDM Tech. Dig., pp. 388-391, 1983.

[60] - "An analytical method for determining intrinsic drain/source resistance of lightly doped drain (LDD) devices," Solid-State Electron., vol. 27, pp. 89-96, Jan. 1984

[61] S. E. Laux, "Accuracy of an effective channel length/external resistance extraction algorithm for MOSFET's," IEEE Trans. Electron Devices, vol. ED-31, pp. 1245-1251, Sept. 1984.

[62] B. J. Sheu et al,, "Source-and-drain series resistance of LDD MOSFET's," IEEE Electron Device Lett., vol. EDL.5, pp. 365-367, Sept. 1984.

[63] P. J. Tsang. J. F. Shepard, J, Lechaton, and S. Ogura, "Characterization of sidewall-spacers formed by anisotropic RIE," J. Electrochem. Soc., vol. 128, p. 238C, 1981; also, P. J. Tsang et al., "Characterization of sidewall-spacers formed by anisotropic RIE,", RNP553, presented at the ECS Spring Meeting, Minneapolis, MN, 1981.

[64] P. J. Tsang, J. F. Shepard, S. Ogura, and J. Riseman, "Sidewall spacer technology," in Proc. ECS Fall Meeting, abstract 233, pp. 373-374, Oct. 1982

[65] R. M. Swanson and J. D. Meindl, "Ion-implanted complementary MOS transistors in low-voltage circuits," IEEE J. Solid-State Circuits, vol. SC-7, Apr. 1972.

[66] Hewlett-Packard Co., TECAP2 Reference Manual, DA355 Mar. 1984

[67] P. I. Suciu and R. L. Johnston, "Experimental derivation of the source and drain resistance of MOS transistors," IEEE Trans. Electron Devices, vol. ED-27, pp. 1846-1848, 1980 .

[68] A. Henning, N. Chan, and J. Plummer, "Substrate current in n-channel and p-channel MOSFET"s between $77 \mathrm{~K}$ and $300 \mathrm{~K}$ : Characterization and simulation," in IEDM Tech. Dig., pp. 573-576, 1985.

[69] J. M. C. Stork and R. D. Isaac, "Bipolar device scaling limits from tunneling in base-emitter junctions," in IEDM Tech. Dig., pp. 404$407,1983$.

[70] F. H. Gaensslen and J. M. Aitken, "Sensitive technique for measuring small MOS gate currents," IEEE Electron Device Lett., vol. EDL1, pp. 231-233, Nov. 1980.

[71] E. Takeda, N. Suzuki, and T. Hagiwara, "Device performance degradation due to hot-carrier injection at energies below the $\mathrm{Si}-\mathrm{SiO}_{2}$ energy barrier," in IEDM Tech. Dig., pp. 396-399, 1983.

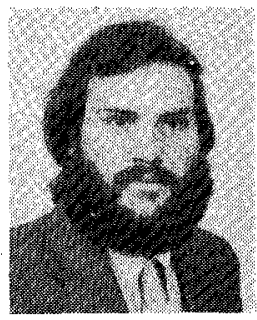

Sergio Bampi (S'86) was born in Brazil. He received the B.Sc. degree in physics and an electronics engineer degree in 1980 from the Federal University of Rio Grande do Sul, and the M.S.E.E. degree in 1982 from Stanford University. He is currently working toward the Ph.D. degree in the Stanford I.C. Laboratory. His dissertation concerns alternative lightly doped drain MOS devices for VLSI. He was awarded a scholarship from the Brazilian Agency $\mathrm{CNPq}$ to pursue graduate studies.

His current research interests are MOS device physics and processes.

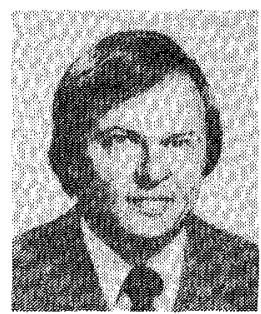

James D. Plummer (M'71-SM'82-F'85) was born in Toronto, Canada, on December 3, 1944. He received the B.S. degree in 1966 from the University of California, Los Angeles, and the M.S and $\mathrm{Ph} . \mathrm{D}$. degrees in electrical engineering from Stanford University in 1967 and 1971, respectively.

He is presently a Professor in the Electrical Engineering Department and is the Director of the Integrated Circuits Laboratory at Stanford University. His current research interests center on basic modeling of semiconductor processes including oxication, epitaxy, and ion implantation, on the physics and technology of scaled bipolar and MOS devices, and on high-voltage devices and integrated circuits. He is the author of numerous technical papers in these areas.

Dr. Plummer is a member of Tau Beta Pi, Sigma Xi, the American Physical Society, and the Electrochemical Society. He has received three best paper awards at the International Solid State Circuits Conference and was the Technical Program Committee Chairman for the 1980 ISSCC. 